\title{
EVALUATION OF DENTAL IMPLANTS USING A MODIFIED THREAD GEOMETRY IN THE MANDIBULAR PREMOLAR REGION
}

\author{
Rana M. Kamel ${ }^{* *} B D S$, Samraa A. El Sheikh² $P h D$, Hala R. Ragab ${ }^{3} P h D$
}

\begin{abstract}
INTRODUCTION: Modern implantology is changing direction towards the development of new implant macrodesigns that are able to provide a high level of physico-mechanical characteristics. This study examines the mechanical aspect of implants. In particular, macrodesign such as thread shape, pitch and depth.

OBJECTIVES: To evaluate clinically and radiographically fin thread design implant osseointegration and primary stability in mandibular premolar region.

MATERIALS AND METHODS: A clinical study was conducted on thirteen patients with missing mandibular premolar teeth. The magic fc implants with fin thread were inserted. After 3 months, final crowns were delivered. All implants were followed for 6 months. Clinically, each patient was evaluated for pain, swelling and stability of the implant. Radiographically, cone beam computed tomography (CBCT) was used for the assessment of marginal bone level and bone density.

RESULTS: There was a significant increase in bone density from immediate postoperative to the end of the 6 months. The mean of marginal bone level from immediately post-operative to the 3rd month was significant and from immediate to 6th month was significant. One case displayed swelling in the first week and the implant was removed (failure case) due to lack of oral hygiene maintenance by the patient.

CONCLUSIONS: Magic FC implants with fin thread were a successful treatment procedure, with satisfactory clinical outcomes, and a low incidence of complications.
\end{abstract}

KEYWORDS: fin threads, primary stability, osseointegration.

1- Dentist, Demonstrator at Pharos University, Faculty of Dentistry, Pharos University, Alexandria, Egypt.

2- Professor, Department of Oral and Maxillofacial Surgery, Faculty of Dentistry, Alexandria University, Egypt.

3- Assistant Professor, Department of Oral and Maxillofacial Surgery, Faculty of Dentistry, Alexandria University, Egypt.

*Corresponding author:

E-mail: ranamansour44@gmail.com

\section{INTRODUCTION}

The success of dental implants depends on the concept of osseointegration introduced by Branemark which implies the structural and functional contact between the implant and the surrounding vital bone (1). According to Alberktsson et al., (2) the six most important factors for establishing a reliable osseointegration are implant material, implant design, surface quality, bone status, surgical technique and loading conditions.

Primary stability is a critical factor that determines the long-term success of dental implants. It is responsible for preventing the micromotion of the implant in the bone site, promoting natural healing and effective bone formation until adequate biological stability has been established. Primary stability of dental implants is highly dependent on implant design, surgical technique and the bone density and quality $(3,4)$.

It is demonstrated that threads have been incorporated into implants to improve the initial contact between implant and bone, enlarge implant surface area and distribute stresses favorably. Implants with more threads achieved greater implant primary stability values (5).

Recently, Fin thread implant design was developed. It was hypothesized that Fin thread design results in better stress distribution (less frictional force), reduced bone trauma and micro-fractures and faster healing time. This achievement results in unprecedented initial stability with no rebound loosening after placement (6).
The present study therefore aimed to evaluate clinical performance of a recently developed implant with a specific Fin thread design for replacement of mandibular premolar teeth.

\section{MATERIALS AND METHODS}

\section{Study design}

This study was conducted on thirteen patients with ages range between (20-40) years with a mean age of (29.46 \pm 5.81 ) years, they were females with missing mandibular premolar teeth indicated for implant placement using two stage surgery. Patients were selected from the Outpatient Clinic of the Oral and Maxillofacial Surgery Department Faculty of Dentistry, Alexandria University.

\section{Inclusion criteria:}

- The patient should be free from any relevant systemic disease that is contraindicated for implant surgery or may affect bone healing.

- Patients with missing mandibular premolar teeth should have adequate bone quality and inter-occlusal space.

- Patients should have adequate oral hygiene and periodontal condition.

\section{Exclusion criteria:}

- Patients with parafunctional habits.

- Heavy smoking patients (more than 10 cigarettes per day) and alcoholism.

\section{Informed consent}

All patients received thorough explanations about the planned treatment and its potential risks and complications, 
and signed a written informed consent form prior to being enrolled in the study. It was also mentioned that the patient had the right of withdrawal from the study anytime without any consequences. Ethical approval for this study was obtained from the research ethics committee, Faculty of Dentistry, Alexandria University before beginning the study.

\section{Materials}

Implant System: Magic fc Dental Implant (IBS: InnoBioSurg Co., Ltd, Korea). The implants used in this study are characterized by a tapered design with modified single threads design "fin threads". The implants (IBS titanium dental implant system) are made of titanium alloy with a RBM (Resorbable Blast Media-sand blasting) surface. They are specially designed for self-tapping which cuts through the bone with no bone chipping while simultaneously condensing the bone, in order to optimize the achievement of primary stability in any type of bone density. The implants for the study were available in lengths of $9 \mathrm{~mm}, 11 \mathrm{~mm}$ and 13mm; the available diameters were 4 $\mathrm{mm}, 4.5 \mathrm{~mm}$ according to the location of the implant placement. (Figure 1)
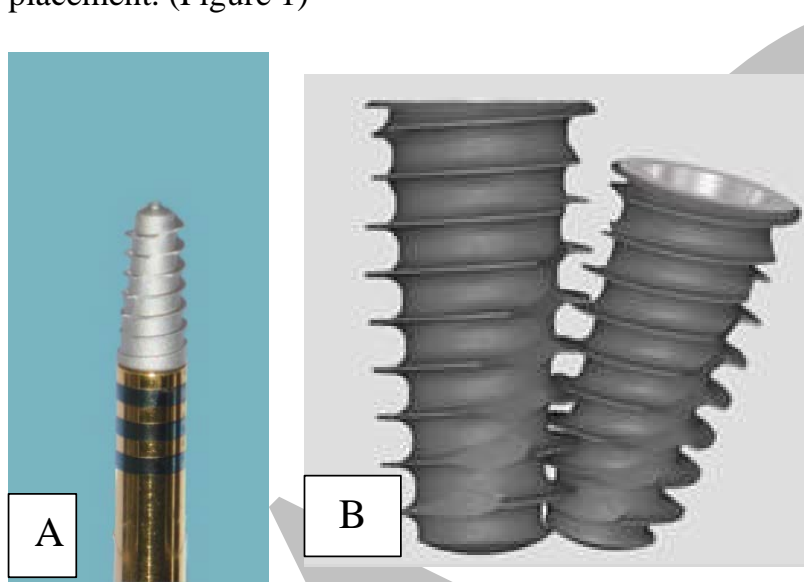

Figure 1: A: Clinical view of magic FC dental implant. B: Magic FC dental implant

\section{Methods}

\section{A) Pre-surgical Phase}

Prior to implant placement, each patient was investigated clinically and radiographically. All patients were subjected to a detailed history taking including: personal data, medical history and dental history. Clinical evaluation of the implant site including inspection, palpation of the edentulous alveolar ridge, the occlusion, and inter-occlusal space. Primary alginate impressions for both arches were taken and diagnostic study models were prepared. Study casts were used for the evaluation of the jaw relationship and the interocclusal space. Pre-operative Cone Beam Computed Tomography (CBCT) was done for all patients to detect any clinically undetectable pathology, approximation to important anatomical structures, Bone width, implant position, angulation and depth.

\section{B) Surgical Phase}

$0.12 \%$ chlorohexidine gluconate mouth wash (Hexitol mouthwash, Arab drug company, Cairo, Egypt) was used to rinse for 30 seconds before operation. All patients were operated under local anaesthesia. Crestal incision was performed and full thickness mucoperiosteal flap was reflected to access the site. The implant bed was prepared using the new specially-designed drill. These drills are available with four drilling lengths $(7,9,11,13 \mathrm{~mm})$ characterized by different color codes, and three different diameters (4, 4.5, $5 \mathrm{~mm})$. They allow a single drilling procedure before implant placement in bone with all types. Drilling speed of 1500 RPM and profuse normal saline irrigation were used throughout the drilling procedure. Tapered implants with an internal connection and RBM treated surface were inserted in all patients with insertion torque $30-50 \mathrm{Ncm}$. Operators are free to choose implant lengths (9, 11 and $13 \mathrm{~mm}$ ) and diameters (4 and $4.5 \mathrm{~mm}$ ) according to clinical indications and their preferences. The SmartPeg was attached to the dental implant for measuring primary stability using Osstell. A cover screw supplied with the implant was inserted on the implant with the use of implant screw driver. Suturing of the flap with interrupted sutures, using 3/0 black silk suturing material. (Figure 2)

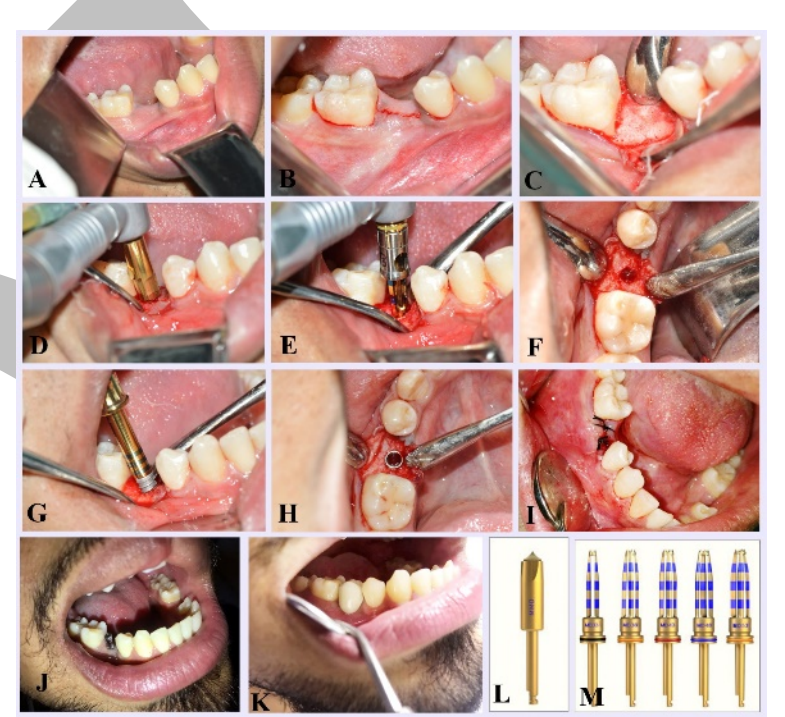

Figure (2): Representative clinical case. A: Clinical preoperative view of the ridge. B,C: Incision and flap reflection. D,E: Magic marking drill and magic drill. F: Preparation of implant site (osteotomy). G,H: Implant placement. I: Suturing. J: Abutment insertion. K: Final porcelain restoration after 3 months postoperative. L: Magic marking drill. M: Magic drill

\section{C) Postsurgical phase}

1.Postoperative instructions including: cold fomentations to the surgical site extraorally for the same day of operation in an intermittent manner every ten minutes for at least 3 hours to minimize postoperative edema and swelling and maintain daily routine oral hygiene after surgery and Patients were instructed to eat a soft diet for 7 days.

All patients received Postoperative medications including

- Broad-spectrum oral antibiotics: Amoxicillin 875 mg / Clavulanic acid 125mg (Augmentin 1gm Tablets, Medical Union Pharmaceuticals (MUP), GlaxoSmithKline, Cairo, Egypt) in a dose of one capsule twice daily for a week

- Non-steroidal anti-inflammatory drugs Ibuprofen 400 mg (Brufen tablet 400mg Abbott, Cairo, Egypt) at a dose of one tablet three times daily for four days.

- Chlorhexidine $0.12 \%$ mouth rinses were prescribed for 2 weeks to enhance plaque control.

\section{Post-operative evaluation}

\section{I.Clinical evaluation}

- Patients were evaluated clinically at interval of one and two weeks postoperatively for Presence of pain using the Visual Analogue scale (VAS) $(7,8)$. Presence of Swelling or infection and implant stability. The implant stability 
measurement was examined immediately at the time of implant insertion and delayed at 3 months postoperatively using the Resonance Frequency Analysis via the Osstell ISQ system (Osstell ${ }^{\circledR}$, integration Diagnostics AB, Goteborg, Sweden.).

\section{II.Radiographic evaluation:}

- Cone beam computed tomography was obtained immediately post-operatively, 3 months and 6 months postoperatively to assess:

1. Bone density around the implant.

- Exposure was performed using "Scanora" (Scanora 3DxSordex-Finland) at $10 \mathrm{MA}, 90 \mathrm{KV}$ and at a proper field of view.

- Image reconstruction was performed using a special software called “Ondemand 3D” (Ondemand 3D: Cybermed, Korea) version 1.0.7. Measurements were taken as follows:

- The bone density apical, buccal and lingual to the implant was used as a known measurement in Hounsfield Unit (HU).

- From the tool bar, the implant bone density was selected from task section.

- The desired area was selected, right click pressed and bone density was chosen.

- Mean, standard deviation, minimum and maximum readings were automatically displayed by the system.

2. Marginal bone level

- A line was drawn just parallel to the implant, starting at the crest of the implant and ending at the apical level of the implant. Height was recorded in millimeter

- The same process was repeated from the lingual direction.

- The mean of the buccal and lingual bone heights was calculated for each implant. (Figure 3)

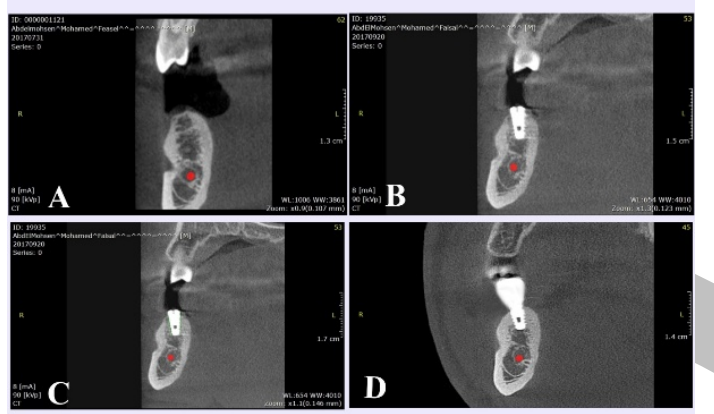

Figure (3): Radiographic follow up of case. A: Preoperative CBCT of implant site. B: Immediate CBCT of implant site postoperatively. C: Third month CBCT of the implant site postoperatively. D: Sixth month CBCT of the implant site postoperatively.

\section{D) Prosthetic phase}

In the second stage surgery the cover screw was removed and the healing abutment was tightened to help gum tissue around the implant heals faster for 1-2 weeks.

After three months, the healing abutment was removed and the abutment was tightened with insertion torque 35 $\mathrm{Ncm}$, and definitive porcelain fused to metal restoration was delivered to all patients

\section{Statistical analysis}

Data were fed to the computer and analyzed using IBM SPSS software package version 20.0 (9) (Armonk, NY: IBM Corp). Quantitative data were described using range, mean, standard deviation and median. The distribution of quantitative variables was tested for normality using Kolmogorov-Smirnov test. The paired t- test was used to compare between two periods showing normally distributed quantitative variables, while the ANOVA with repeated measures was used to compare between more than two periods or stages, and Bonferroni Post Hoc test. The Friedman test was used for abnormally distributed quantitative variables, with Dunn's Post Hoc Test. Significance of the obtained results was judged at the $5 \%$ level.

\section{RESULTS}

Thirteen patients with extracted mandibular premolar teeth indicated for implant placement were evaluated in this study. Their ages ranged from 20 to 40 years. They were females. Thirteen implants were placed; 4 mm diameter $\times 9$ $\mathrm{mm}$ length were placed in four patients, $4.5 \mathrm{~mm}$ diameter $\times 9 \mathrm{~mm}$ length were placed in six patients, $4.5 \mathrm{~mm}$ diameter $\times 11 \mathrm{~mm}$ length were placed in two patients and $4 \mathrm{~mm}$ diameter $\times 13 \mathrm{~mm}$ length were placed in one patients.

All patients were followed up for six months and the results were registered as regards: clinical evaluation and radiographic evaluation.

\section{I.Clinical evaluation}

1. Presence of pain: Pain was evaluated daily for two weeks using visual analogue scale (VAS) from 0 to 10 ("0" is pain free and "10" is unbearable pain). After surgery, five patients experienced mild pain (VAS=2-4), three patients experienced moderate pain $(\mathrm{VAS}=5-7)$, one patient experienced severe pain and four patients experienced no pain at surgical site for 1-3 days duration.

During the follow up period, all patients felt no pain after implant placement except one case that felt severe postoperative pain in the first week after implant placement. 2. Presence of Swelling: In only one case, swelling in the operated area was found in the first week of implant placement (failure case). In the other cases, patients continued the follow up period without clinical signs of inflammation, peri-implant infections after implant placement or during the evaluation period.

3. Implant stability quotient (ISQ) (Table 1, figure 4) Implant stability quotient was measured in all patients using the resonance frequency analysis technique by the Osstell device immediately after implant placement and 3 months. The data was collected and tabulated and the statistical analysis was done for all patients. The mean implant stability quotient at day of surgery was $72.29 \pm 5.07$. There was an increase in 3rd month post-operatively 76.67 \pm 6.75 .

The implant stability quotient (ISQ) increased in 3rd month. The increase in implant stability quotient in three months was statistically significant.

One implant was removed in the first week that was regarded as a failure case.

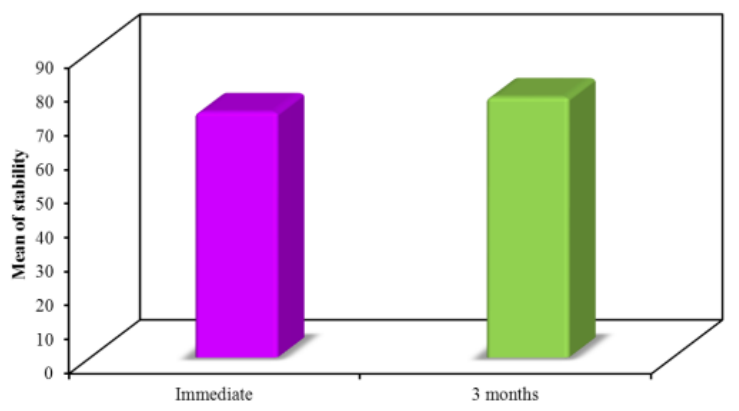

Figure (4): Comparison between the two studied periods according to stability 
Table (1): Comparison between the two studied periods according to stability

\begin{tabular}{|l|c|c|c|c|}
\hline Stability & $\begin{array}{c}\text { Immediate } \\
(\mathbf{n}=\mathbf{1 2})\end{array}$ & $\begin{array}{c}\text { 3 months } \\
(\mathbf{n}=\mathbf{1 2})\end{array}$ & T & P \\
\hline Min. - & $63.0-79.0$ & $66.0-87.0$ & & \\
Max. & & & $2.330^{*}$ & $0.040^{*}$ \\
$\begin{array}{l}\text { Mean } \pm \\
\text { SD }\end{array}$ & $72.29 \pm 5.07$ & $76.67 \pm 6.75$ & & \\
Median & 73.0 & 78.50 & & \\
\hline Diff. & \multicolumn{2}{|c|}{$4.38 \pm 6.51$} & & \\
\hline \% & \multicolumn{2}{|c|}{$\uparrow .26 \pm \mathbf{8 . 8 4}$} & & \\
Change & & &
\end{tabular}

t: Paired t-test

$\mathrm{p}$ : $\mathrm{p}$ value for comparing between immediate and after 6 months

*: Statistically significant at $\mathrm{p} \leq 0.05$

\section{II.Radiographic Evaluation:}

\section{Bone density}

Data were collected regarding mean peri-implant bone density values, standard deviation and percentage of change at immediate, 3 months and 6 months. (Tables 2, Figure 5)

In the immediate post-operative phase, the mean periimplant bone density was $808.08 \pm 168.31 \mathrm{HU}$ with a minimum recorded value of $521.13 \mathrm{HU}$ and a maximum recorded value of $1018.83 \mathrm{HU}$.

In the third month, the mean peri-implant bone density was $868.84 \pm 136.22 \mathrm{HU}$ with a minimum recorded value of 649.03 HU and a maximum recorded value of $1066.60 \mathrm{HU}$.

In the sixth month, the mean peri-implant bone density was $967.19 \pm 123.48 \mathrm{HU}$ with a minimum recorded value of 783.40 and a maximum recorded value of $1133.53 \mathrm{HU}$. These differences were statistically significant $(\mathrm{p}<0.05)$.

Table (2): Comparison between the three studied periods according to bone density

\begin{tabular}{|c|c|c|c|c|c|}
\hline $\begin{array}{c}\text { Bone } \\
\text { density }\end{array}$ & $\begin{array}{c}\text { Immediat } \\
\text { e } \\
(n=12)\end{array}$ & $\begin{array}{c}3 \text { Months } \\
(\mathrm{n}=12)\end{array}$ & $\begin{array}{l}6 \text { Months } \\
(n=12)\end{array}$ & $\mathbf{F}$ & $\mathbf{p}$ \\
\hline $\begin{array}{l}\text { Min. - Max. } \\
\text { Mean } \pm \text { SD } \\
\text { Median }\end{array}$ & $\begin{array}{c}521.13- \\
1018.83 \\
808.08 \pm 16 \\
8.31 \\
786.08\end{array}$ & $\begin{array}{c}649.03- \\
1066.60 \\
868.84 \pm 136 . \\
22 \\
849.63\end{array}$ & $\begin{array}{c}783.40- \\
1133.53 \\
967.19 \pm 123 \\
48 \\
981.85\end{array}$ & $\begin{array}{c}19.38 \\
5^{*}\end{array}$ & $\begin{array}{c}<0.00 \\
1^{*}\end{array}$ \\
\hline \% Change & & $\uparrow 8.96 \pm 9.12$ & $\begin{array}{c}\uparrow 22.70 \pm 18.8 \\
9\end{array}$ & & \\
\hline $\begin{array}{l}\text { Sig. bet. } \\
\text { periods. }\end{array}$ & \multicolumn{3}{|c|}{$\mathrm{p}_{1}=0.006^{*}, \mathrm{p}_{2}=0.002^{*}, \mathrm{p}_{3}=0.010^{*}$} & & \\
\hline
\end{tabular}

F: F test (ANOVA) with repeated measures

$\mathrm{p}$ : $\mathrm{p}$ value for comparing between the three studied periods $\mathrm{p}_{1}$ : $\mathrm{p}$ value for comparing between immediate and 3 Months p2: $p$ value for comparing between immediate and 6 Months p3: p value for comparing between 3 Months and 6 Months

*: Statistically significant at $\mathrm{p} \leq 0.05$

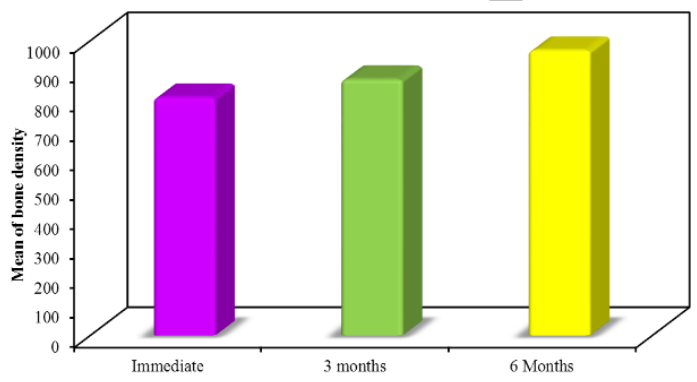

Figure (5): Comparison between the three studied periods according to bone density

2. Marginal bone level
Data were collected regarding the marginal bone level at the mesial and distal aspects of all implants at immediate, 3 months and 6 months.

The data collected was tabulated and the statistical analysis of the marginal bone level scores was done for all patients. (Tables 3, Figure 6)

In the immediate postoperative phase, the mean marginal bone level (MBL) value was $9.60 \pm 1.06 \mathrm{~mm}$ with a minimum-recorded value of $8.60 \mathrm{~mm}$ and a maximumrecorded value of $11.56 \mathrm{~mm}$.

In the third month, the mean MBL value was 9.09 \pm 1.09 $\mathrm{mm}$ with a minimum-recorded value of $8.19 \mathrm{~mm}$ and a maximum-recorded value of $11.12 \mathrm{~mm}$.

In the sixth month, the mean MBL value was $8.71 \pm 1.05$ $\mathrm{mm}$ with a minimum-recorded value of $7.74 \mathrm{~mm}$ and a maximum-recorded value of $10.67 \mathrm{~mm}$. These differences were statistically significant $(\mathrm{p}<0.05)$.

Table (3): Comparison between the three studied periods according to marginal bone level.

\begin{tabular}{|c|c|c|c|c|c|}
\hline $\begin{array}{l}\text { Marginal } \\
\text { bone level }\end{array}$ & $\begin{array}{c}\text { Immediat } \\
\mathbf{e} \\
(\mathrm{n}=12)\end{array}$ & $\begin{array}{l}3 \text { Months } \\
(\mathrm{n}=12)\end{array}$ & $\begin{array}{c}6 \\
\text { Months } \\
(n=12)\end{array}$ & $\mathbf{F}$ & $\mathbf{P}$ \\
\hline $\begin{array}{l}\text { Min. - } \\
\text { Max. } \\
\text { Mean } \pm \text { SD } \\
\text { Median } \\
\end{array}$ & $\begin{array}{c}8.60- \\
11.56 \\
9.60 \pm 1.06 \\
9.07 \\
\end{array}$ & $\begin{array}{c}8.19-11.12 \\
9.09 \pm 1.09 \\
8.59\end{array}$ & $\begin{array}{c}7.74- \\
10.67 \\
8.71 \pm 1.0 \\
5 \\
8.27 \\
\end{array}$ & $\underset{*}{100.430}$ & $<0.001^{*}$ \\
\hline \% Change & & \begin{tabular}{|c|}
$\downarrow 5.30 \pm 2.7$ \\
8
\end{tabular} & $\begin{array}{c}\downarrow 9.28 \pm 2 . \\
49\end{array}$ & & \\
\hline $\begin{array}{l}\text { Sig. bet. } \\
\text { periods. }\end{array}$ & \multicolumn{3}{|c|}{$\mathrm{p}_{1}<0.001^{*}, \mathrm{p}_{2}<0.001^{*}, \mathrm{p}_{3}<0.001^{*}$} & & \\
\hline
\end{tabular}

F: F test (ANOVA) with repeated measures

$\mathrm{p}: \mathrm{p}$ value for comparing between the three studied periods $\mathrm{p}_{1}$ : $\mathrm{p}$ value for comparing between immediate and 3 Months p2: $\mathrm{p}$ value for comparing between immediate and 6 Months $\mathrm{p}_{3}$ : $\mathrm{p}$ value for comparing between 3 Months and 6 Months

*: Statistically significant at $\mathrm{p} \leq 0.05$

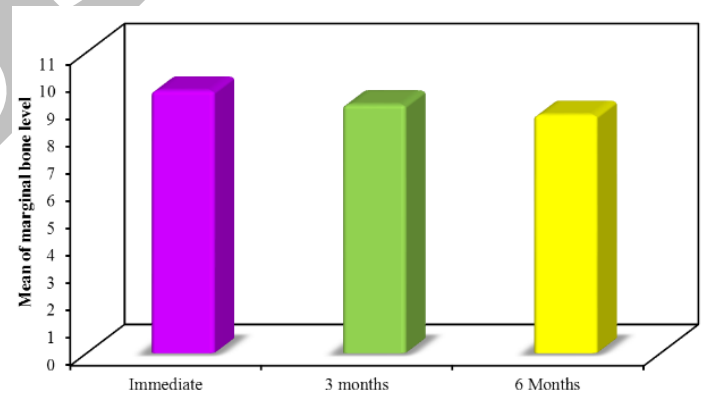

Figure (6): Comparison between the three studied periods according to marginal bone level

\section{DISCUSSION}

This present study was conducted on thirteen patients in need for implant placement for their lost mandibular premolar teeth with adequate bone quality and interocclusal space. They were selected from the Outpatient Clinic of the Oral and Maxillofacial Surgery Department, Faculty of Dentistry, Alexandria University.

The selected patients were free from any systemic diseases or a condition that may complicate the surgical procedure or the healing process of the implant this was following Bornstein et al., (10) in 2009 where they reviewed whether systemic diseases with/without systemic medication increase the risk of implant failure and therefore diminish success and survival rates of dental implants. 
All cases in the present study were selected free from parafunctional habits such as bruxism and clenching, which increase the magnitude of the forces. In such patients, the duration of the forces is extensive, and their direction is more horizontal than axial to the implants, which leads to mechanical complications and failure of implants according to Manfredini et al., (11) in 2014.

Various imaging options are available for the evaluation of the recipient site. In the present study, CBCT was taken for each patient. CBCT was taken immediately post-operative, on 3rd and 6th month follow-up period to measure the marginal bone level and to detect the changes in bone density surrounding dental implants.

In this study CBCT was performed for all patients preoperatively. Corresponding to the studies conducted by Cassetta et al., (12) in 2013 and Bornstein et al., (13) in 2014, they reported that the use of CBCT in implant dentistry vary from preoperative analysis regarding anatomic considerations, and treatment planning to postoperative evaluation. Along with, lower radiation dose, reduced costs and the relative grey density values of CBCT images making it a useful substitute for computerized tomography (CT) $(14,15)$.

As regards the surgical procedure, All implants were inserted according to the manufacturer's recommendations, and the drilling was performed under profuse irrigation using normal saline for proper cooling and to avoid overheating of the bone tissues which would compromise osseointegration in accordance to Strbac et al., in 2014 (16). This also matches findings obtained by Lee et al., in 2012 (17) and Augustin et al., in 2012. (18)

In the present study, the implant stability was measured using the Resonance Frequency Analysis (RFA) via the Osstell ISQ system immediately and 3 months postopertively. RFA was chosen as a non-invasive and reliable method to assess variation in implant stability over time. RFA registrations are directly related to the stiffness of the implant in the surrounding bone: during healing an increase in implant stability quotient (ISQ) values presumably reflect new bone apposition at the implant-bone interface $(19,20)$.

Meredith et al., $(19,21)$ in 1996 and 1997 supporting this review when stated that RFA can serve as a useful research technique and may prove to be valuable in studying the behavior of implants in surrounding tissue. In this study a noncontacting method was used allowing the testing of the implant stability from any surface in $360^{\circ}$ around the implant fixture.

These results were in agreement with Torroella-Saura et al., in 2015(22) reported that tapered implants achieved higher primary stability values compared with the cylindrical implants measured. These results are in accordance with similar studies of O'Sullivan et al., in 2000 (23), Akca et al., in 2006 (24), Sakoh et al., in 2006 (25), Chong et al., in 2009 (26) and Toyoshima et al., in 2011(27) comparing tapered and cylindrical implants in primary stability.

Regarding the presence of pain, Pain was evaluated daily for two weeks using visual analogue scale (VAS) from 0 to 10 ("0" is pain free and "10" is unbearable pain). After surgery, five patients experienced mild pain (VAS=2-4), three patients experienced moderate pain (VAS=5-7), one patient experienced severe pain and four patients experienced no pain at surgical site for 1-3 days duration. During the follow up period, all patients felt no pain after implant placement except one case that felt severe postoperative pain in the first week after implant placement.

These results are in accordance with the studies performed by Hashem et al., in 2006 (28) and Karabuda et al., in 2007 (29) they stated that pain following implant placement ranged from mild to moderate on VAS. In both studies, the peak of pain perception occurred on day one following surgery.

From the clinical evaluation, which was extended up to 2 weeks, regarding the presence of Swelling, only one implant displayed swelling in the operated area after one week and needed removal (failure case). The failed implant was in the first premolar teeth of a female patient.

As reported by Al-Sabbagh and Bhavsar in 2015 (30) that the clinical signs of peri-implant infection are considered to be associated with implant failures.

Early swelling around the implant and failure of this case could be attributed to lack of oral hygiene maintenance by the patient in spite of the instructions given to her.

The present study showed statistically significant increase in peri-implant bone density from the immediate postoperative period to the end of the 6 months of the evaluation period, which indicates successful osseointegration around the implants.

These results were in agreement with the results of Yunus (31) in 2011. In his study, 30 patients were evaluated using CT to determine the changes of jaw bone density around the dental implant after placement. The study concluded that bone density around dental implant was increased after placement. The increased rate of bone density could be determined by the quality of jaw bone before implant placement.

Regarding peri-implant bone level, there was statistically significant difference in the mean of periimplant bone level changes from immediate postoperative to the 3rd month. The change of MBL from immediate post-operative to 6 months was statistically significant. The difference from the 3rd month to 6th month was statistically significant.

The findings confirmed that dental implant macrodesign features, in particular the thread pattern can be responsible for minimization of the micromotion and stresses around the implant, and ultimately may impact the success of the establishment and/or maintenance of implant osseointegration.

After clinical and radiographical evaluation we were able to evaluate the implant success. The successful magic fc dental implant with fin thread demonstrated absence of persistent or irreversible signs and symptoms such as pain, infections, neuropathies, and absence of peri-implant radiolucency. Also, $1 \mathrm{~mm}$ of bone loss from the implant head was acceptable during the first year and less than 0.2 $\mathrm{mm}$ bone loss annually thereafter.

According to Esposito et al., in 1998 (32) following were to be considered success criteria for osseointegrated implants: Absence of pain/paresthesia and an average radiographic marginal bone loss of less than $1.5 \mathrm{~mm}$ during the first year of function. Less than $0.2 \mathrm{~mm}$ annually thereafter.

\section{CONCLUSION}

Within the limits of this study, the overall conclusion that can be drawn from this study is that magic fc dental implant with fin thread is a predictable treatment procedure, with 
good survival rates (92.3\%) and a low incidence of complications.

\section{CONFLICT OF INTEREST}

The authors declare that they have no conflicts of interest.

\section{REFERENCES}

1-Adell R, Lekholm U, Rockler B, Branmark OI. A 15-year study of osseointegarted implants in the treatment of the edentulous jaw. Int J Oral Surg. 1981;10:387-416.

2-Albrektsson T. direct bone anchorage of dental implant. J Prosthet Dent 1983; 50: 255-61

3-O'Sullivan D, Sennerby L, Jagger D, Meredith N. Comparison of two methods of enhancing implant primary stability. Clin Implant Dent Relat Res. 2004;6:48-57.

4-Szmukler-Moncler S, Salama H, Reingewirtz Y, Dubruille JH. Timing of loading and effect of micro-motion on boneimplant interface. A review of experimental literature. J Biomed Mat Res. 1998;43:192-203.

5-Orsini E, Salgarello S, Bubalo M, Lazic Z, Trire A, Martini $D$, et al. Histomorphometric evaluation of implant design as a key factor in peri-implant bone response: a preliminary study in a dog model. Minerva Stomatologica. 2009;58:263-75.

6-IBS implant, Dream Series, H-1 drill - Suppliers of dental implant, fixture from South Korea. IBS Implant. 2010. Available at: http://ibsimplant.blogspot.com.eg/

7-Grossman SA, Sheidler VR, McGuire DB, Geer C, Santor D, Piantadosi S.A comparison of the Hopkins Pain Rating Instruments with standard visual analogue and verbal descriptor scales in patients with cancer pain. J Pain Symptom Manage. 1992;7:196-203.

8-Le Resche L, Burgess J, Dworkin SF. Reliability of visual analoge and verbal descriptor scales for "objective" measurement of tempromandibular disorder pain. J Dent Res. 2000;67:33-6.

9-Kirkpatrick LA, Feeney BC. A simple guide to IBM SPSS statistics for version 20.0. Student ed. Belmont, Calif.: Wadsworth, Cengage Learning; 2013.

10-Bornstein MM, Cionca N, Mombelli A. Systemic conditions and treatments as risks for implant therapy. Int $\mathrm{J}$ Oral Maxillofac Implants. 2009;24:12-27.

11-Manfredini D, Poggio CE, Lobbezoo F. Is bruxism a risk factor for dental implants? A systematic review of the literature. Clin Implant Dent Relat Res. 2014;16:460-9.

12-Cassetta M, Sofan AA, Altieri F, Barbato E. Evaluation of alveolar cortical bone thickness and density for orthodontic mini-implant placement. J Clin Exp Dent. 2013;5: 245-52.

13-Bornstein MM, Scarfe WC, Vaughn VM, Jacobs R. Cone beam computed tomography in implant dentistry: a systematic review focusing on guidelines, indications, and radiation dose risks. Int J Oral Maxillofac Implants. 2014;29:55-77.

14-Pedroso LA, Garcia RR, Leles JLR, Leles CR, Silva MAGS. Impact of cone-beam computed tomography on implant planning and on prediction of implant size. Braz Oral Res. 2014;28:46-53.

15-Chasioti E, Sayed M, Drew H. Novel techniques with the aid of a staged CBCT guided surgical protocol. Case Rep Dent. 2015;2015:439706.

16-Strbac GD, Unger E, Donner R, Bijak M, Watzek G, Zechner $\mathrm{W}$. Thermal effects of a combined irrigation method during implant site drilling. A standardized in vitro study using a bovine rib model. Clin Oral Implants Res. 2014;25:665-74.
17-Lee J, Ozdoganlar OB, Rabin Y. An experimental investigation on thermal exposure during bone drilling. Med Eng Phys. 2012;34:1510-20.

18-Augustin G, Davila S, Udillijak T, Staroveski T, Brezak D, Babic S. Temperature changes during cortical bone drilling with a newly designed step drill and an internally cooled drill. Int Orthop. 2012;36:1449-56.

19-Meredith N, Books K, Fribergs B, Jemt T, Sennerby L. Resonance frequency measurements of implant stability in viva. A cross-sectional and longitudinal study of resonance frequency measurements on implants in the edentulous and partially dentate maxilla. Clin Oral Implants Res. 1997;8:226-33.

20-Sim CP, Lang NP. Factors influencing resonance frequency analysis assessed by Osstell ${ }^{\mathrm{TM}}$ mentor during implant tissue integration: I. Instrument positioning, bone structure, implant length. Clin Oral Implants Res. 2010;21:598-604.

21-Meredith N, Alleyne D, Cawley P. Quantitative determination of the stability of the implant tissue interface using resonance frequency analysis. Clin Oral Implants Res. 1996;7:261-7.

22-Torroella-Saura G, Mareque-Bueno J, Cabratosa-Termes J, Hernández-Alfaro F, Ferrés-Padró E, Calvo-Guirado JL. Effect of implant design in immediate loading. A randomized, controlled, split-mouth, prospective clinical trial. Clin Oral Implants Res. 2015;26:240-4.

23-O’Sullivan D, Sennerby L, Meredith N. Measurements comparing the initial stability of five designs of dental implants: a human cadaver study. Clin Implants Dent Relat Res. 2000;2:85-92.

24-Akca K, Chang TL, Tekdemir I, Fanuscu MI. Biomechanical aspects of initial intraosseous stability and implant design: a quantitative micro-morphometric analysis. Clin Oral Implants Res. 2006;17:465-72.

25-Sakoh J, Wahlmann U, Stender E, Nat R, Al-Nawas B, Wagner W. Primary stability of a conical implant and a hybrid, cylindric screw-type implant in vitro. Int J Oral Maxillofac Implants. 2006;21:560-6.

26-Chong L, Khocht A, Suzuki JB, Gaughan J. Effect of implant design on initial stability of tapered implants. J Oral Implantol. 2009;35:130-5.

27-Toyoshima T, Wagner W, Klein MO, Stender E, Wieland M, Al-Nawas B. Primary stability of a hybrid self-tapping implant compared to a cylindrical non-self-tapping implant with respect to drilling protocols in an Ex vivo model. Clin Implant Dent Relat Res. 2011;13:71-8.

28-Hashem AA, Claffey NM, O'Connell B. Pain and anxiety following the placement of dental implants. Int J Oral Maxillofac Implants. 2006;21:943-50.

29-Karabuda ZC, Bolukbasi N, Aral A, Basegmez-Zeren C, Ozdemir T. Comparison of analgesic and anti-inflammatory efficacy of selective and non-selective cyclooxygenase-2 inhibitors in dental implant surgery. J Periodontol. 2007;78:2284-8.

30-Al-Sabbagh M, Bhavsar I. Key local and surgical factors related to implant failure. Dent Clin North Am. 2015;59:1-23.

31-Yunus B. Assessment of the increased calcification of the jaw bone with CT-Scan after dental implantplacement. Imaging Sci Dent. 2011;41:59-62.

32-Esposito M, Hirsch J-M, Lekholm U, Thomsen P. Biological factors contributing to failures of osseointegrated oral implants. (I) Success criteria and epidemiology. Eur J Oral Sci. 1998;106:527-51. 